\title{
Genetic and environmental variation in the $L H$ response of ovariectomized sheep to LH-RH
}

\author{
R. B. Land, W. R. Carr and R. Thompson* \\ A.R.C. Animal Breeding Research Organisation, Field Laboratory, Roslin, Midlothian EH25 \\ 9PS, and *A.R.C. Unit of Statistics, West Mains Road, Edinburgh, U.K.
}

\begin{abstract}
Summary. The influence of breed and season on the sensitivity of the pituitary gland of sheep to LH-RH was assessed. Ovariectomized ewes of 3 breeds (Finnish Landrace, Scottish Blackface and Tasmanian Merino) with differing normal breeding seasons and with differing ovulation rates were injected (i.v.) with 3 doses of LH-RH $(1.56,6.25$ or $25.0 \mu \mathrm{g})$ at 3 different times of the year covering the anoestrous and the breeding seasons of intact ewes; 9 ewes of each breed ( 3 per sub-class) were examined on the first and third occasions, 6 ( 2 per sub-class) on the second. The response was measured in terms of the concentration of $\mathrm{LH}$ in peripheral plasma 20, 40, 60 and $80 \mathrm{~min}$ after injection. Time of year, but not the breed of sheep, affected the magnitude of the response; the data indicated that the duration of LH secretion was greater during the breeding season than during anoestrus. It was concluded that changes in the spontaneous activity of the hypothalamus/hypophysis could contribute to seasonal changes in LH secretion independently of the modifying effects of gonadal steroids. Such variation in unmodulated activity apparently does not contribute to the differences in ovulation rate among the 3 breeds.
\end{abstract}

\section{Introduction}

Genetic and seasonal variation in the reproductive activity of the sheep may be independent of marked differences in the pattern of LH secretion. For example, Yuthasastrakosol, Palmer \& Howland (1977) report that both frequency and size of the LH peaks was similar at 'mid' and 'late' anoestrus; Land, Pelletier, Thimonier \& Mauleon (1973) found that the concentration of LH in peripheral plasma was similar in breeds of sheep differing up to 3-fold in fecundity. One of the major difficulties in comparing seasons and breeds however is the separation of secondary changes from primary causes. Differences between oestrous and anoestrous sheep could be the cause of the respective presence and absence of oestrous cycle, or merely the consequence; differences among breeds of differing fecundity could be the source of variation in ovulation rate or again merely follow the presence of differing numbers of developing follicles and corpora lutea. To some extent these difficulties may be overcome by attempting to separate the components of reproduction, for example into variation in the 'spontaneous activity' of the hypothalamus and hypophysis, and into variation in the extent to which their activity is modulated by the feed-back effects of gonadal steroids. By removing the ovaries, the latter source of variation can be excluded, and it has been found that sensitivity to positive feed-back varies with both the season of study and the breed of sheep (Land, Wheeler \& Carr, 1976). The contribution of variation in the LH-RH sensitivity of the hypophysis to such variation has now been assessed by measuring the concentration of $\mathrm{LH}$ in peripheral plasma following the injection of exogenous LH-RH to ovariectomized ewes of 3 breeds at 3 different times of the year.

\section{Materials and Methods}

Nine (9) ewes of each of the Tasmanian Merino (Merino), Scottish Blackface (Blackface) and Finnish Landrace (Finn) breeds were studied. These breeds were chosen for the large difference in their ovulation rates (Merino, 1.1; Blackface, 1.3; Finn, 3.0) and for the different times of 
onset of their breeding seasons (Wheeler \& Land, 1977). All ewes were ovariectomized to remove the effects of variation in the concentration of ovarian steroids in peripheral plasma on the sensitivity of the pituitary gland to LH-RH. The ewes were 4 to $4 \frac{1}{2}$ years of age at the time of study and had been ovariectomized when $3 \frac{1}{2}$ years old. They were maintained throughout at the ABRO Dryden Field Laboratory under conditions similar to those used for the sheep studied by Wheeler \& Land (1977) and in which normal seasonal and breed variation in reproductive activity of intact ewes would be expected to be expressed.

Each sheep was allocated to one of three doses, 1.56, 6.25 or $25.0 \mu \mathrm{g}$, of LH-RH (Hoechst Pharmaceuticals), made up to $2 \mathrm{ml}$ and given by intravenous injection. Blood samples were collected by acute puncture of the jugular vein before, and $20,40,60$ and $80 \mathrm{~min}( \pm 2 \mathrm{~min})$ after LH-RH injection. The plasma was removed within $40 \mathrm{~min}$ and stored frozen until assayed for LH, using a specific rabbit anti-ovine LH antiserum and purified LH for labelling (M3: Jutisz \& Courte, 1968). The method used and specificity of the antiserum have been described previously (Carr \& Land, 1975). To avoid between-assay variation, all samples were tested in one assay and the results computed by the ABRO Radioimmunoassay Programme package. A diluted plasma sample, prepared from blood taken from an ovariectomized ewe, was used as control and the dose-response curve was examined and compared with that obtained by the NIH-LH-S18 standards, after logit-log transformation. The gradients were -1.154 (s.e. \pm 0.059 ) and -1.074 (s.e. \pm 0.054 ) for control and standards respectively. Consequently, the hypothesis of parallelism was not rejected, and the pooled gradient was -1.089 (s.e. \pm 0.0435 ). The overall potency estimate for the control sample was $6 \cdot 13(5 \cdot 23-7 \cdot 13,95 \%$ confidence limits) and the minimum detectable dose was found to be $0.28 \mathrm{ng} / \mathrm{ml}$ based on the optimization procedure devised by Rodbard (1971).

The response to LH-RH was measured at three times of the year, in early June, late August and early November 1975 (i.e. at 10-week intervals), covering both the anoestrous period and the breeding season of intact ewes. All animals were studied in June and November, but only 6 per breed, taken at random, were used in August; the sheep were allocated equally to all dosebreed sub-classes at each time of the year. Sheep studied in August received the same dose as they had been given in June; in November they usually received a dose different from that given in June. The data were analysed by analysis of variance.

Sums of squares for breeds, time of year and doses and two-factor interactions between these factors were calculated using the method of proportional sub-class numbers (Snedecor \& Cochran, 1967, p. 478). Sums of squares for sheep were calculated by introducing dummy covariates (Finney, 1960). Expected values for the mean squares, in terms of the within-sheep variance $\left(\sigma_{\mathrm{e}}^{2}\right)$ and between-sheep component $\left(\sigma_{\mathrm{s}}^{2}\right)$, were calculated using algebra similar to that given by Snedecor \& Cochran $(1967$, p. 364) and are given in Table 1. The residual and sheep mean squares were used to give estimates of $\sigma_{\mathrm{e}}^{2}$ and $\sigma_{\mathrm{s}}^{2}$ and hence expected values of the treatment mean squares. Variance ratios were calculated by dividing the treatment mean squares by their expected values. For example, for the data in Table 1 the residual and sheep mean squares of 1459 and 7827 , estimate $\sigma_{\mathrm{e}}^{2}$ and $\sigma_{\mathrm{e}}^{2}+2 \cdot 1 \sigma_{\mathrm{s}}^{2}$. Hence estimates of $\sigma_{\mathrm{e}}^{2}$ and $\sigma_{\mathrm{s}}^{2}$ are 1459 and $(7827-1459) / 2 \cdot 1$. The expected value of the breed mean squares is then $\sigma_{\mathrm{e}}^{2}+2 \cdot 75 \sigma_{\mathrm{s}}^{2}$ (Table 1), which equals $1459+2.75 \times 3016=9754$ and the variance ratio is $9378 / 9754=$ 0.96 . Analyses were carried out on the $\mathrm{LH}$ concentration at each time after injection, the sum of the four concentrations ('summed concentration') as an estimate of the whole response, and on linear and quadratic trends over time.

\section{Before treatment}

\section{Results}

The over-all mean concentration of $\mathrm{LH}$ before treatment was $6.83 \mathrm{ng} / \mathrm{ml}$. The concentration was not affected by the breed of sheep studied or the time of year when it was studied $(P>0.05)$. 
Table 1. Summary of the analysis of variation in the concentration of LH following the injection of LH-RH at 3 'seasons' of the year, expressed as the sum of the concentrations at each of the 4 times after injection

\begin{tabular}{lcrcr}
\hline Source of variation & d.f. & MS & EMS & VR \\
\hline Breed & 2 & 9378 & $\sigma_{\mathrm{e}}^{2}+2.75 \sigma_{\mathrm{s}}^{2}$ & 0.96 \\
Dose & 2 & 180755 & $\sigma_{\mathrm{e}}^{2}+1.58 \sigma_{\mathrm{s}}^{2}$ & 29.04 \\
'Season' & 2 & 6067 & $\sigma_{\mathrm{e}}^{2}+0.13 \sigma_{\mathrm{s}}^{2}$ & 3.36 \\
Breed $\times$ Dose & 4 & 3588 & $\sigma_{\mathrm{e}}^{2}+1.58 \sigma_{\mathrm{s}}^{2}$ & 0.58 \\
Breed $\times$ Season & 4 & 4509 & $\sigma_{\mathrm{e}}^{2}+0.13 \sigma_{\mathrm{s}}^{2}$ & 2.46 \\
Dose $\times$ Season & 4 & 8246 & $\sigma_{\mathrm{e}}^{2}+0.71 \sigma_{\mathrm{s}}^{2}$ & $2 \cdot 29$ \\
Sheep & 24 & 7827 & $\sigma_{\mathrm{e}}^{2}+2 \cdot 11 \sigma_{\mathrm{s}}^{2}$ & \\
Residual & 29 & 1459 & $\sigma_{\mathrm{e}}^{2}$ & \\
\hline
\end{tabular}

\section{After treatment}

Dose. The effect of the dose of LH-RH on the concentration of LH was first examined using the sum of the concentrations at the four sampling times after injection as a single variable ('summed concentration') and a summary of the analysis of variance is given in Table 1. The 'summed concentration' was markedly affected by the dose of LH-RH, the mean summed concentrations following treatment with each dose pooled over the three breeds and time of year being $152.7(1.56 \mu \mathrm{g}), 262.6(6.25 \mu \mathrm{g})$ and $323.9(25 \mu \mathrm{g}) \mathrm{ng} / \mathrm{ml}$. The characteristics of the average response to the three doses over the three breeds and times of year is illustrated in Textfig. 1 . In addition to the greater summed concentration following the injection of $25 \mu \mathrm{g} \mathrm{LH}-\mathrm{RH}$, the shape of the response curve appeared to differ from that following the injection of $1.56 \mu \mathrm{g}$; the reality of this difference is supported by a statistically significant $(P<0.05)$ effect of dose on the quadratic component of the curve.

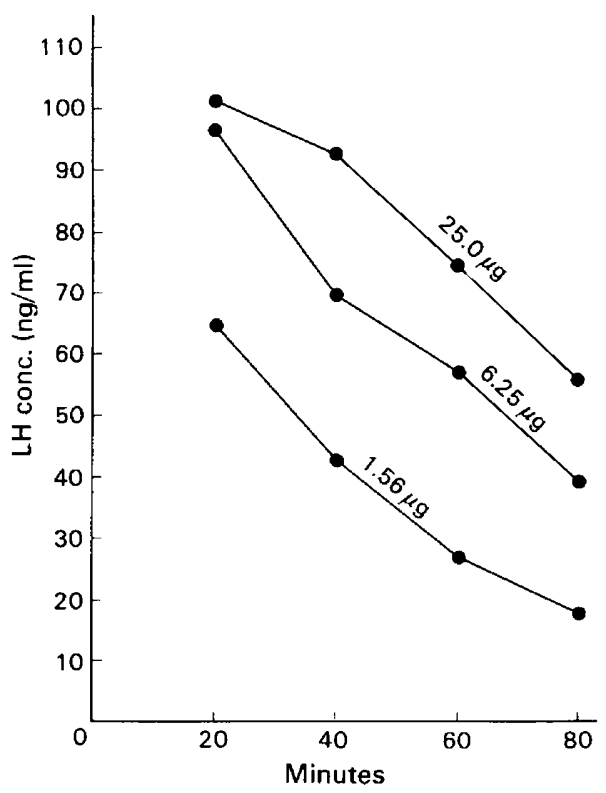

Text-fig. 1. The effect of dose of LH-RH (at $0 \mathrm{~min}$ ) on the average $\mathrm{LH}$ response of Finn, Blackface and Merino ewes. 
Breed. There was no statistically significant effect of the breed of sheep on the magnitude of the response to LH-RH (Table 1). The 'summed concentration' over seasons varied only from 224.6 (Merino) to $263.1 \mathrm{ng} / \mathrm{ml}$ (Blackface), the standard error of the breed totals being 28.5 $\mathrm{ng} / \mathrm{ml}$, calculated from the pooled variation between sheep within groups.

The characteristics of the response of the 3 breeds were studied further by analysing the variation in the concentration at individual sampling times after treatment. The mean concentration at each sampling time pooled over the 3 times of year is illustrated in Text-fig. 2 for each of the 3 breeds, and it can be seen that the characteristics of the response appear basically similar. This apparent similarity of the magnitude of the response of the sheep of the three breeds is supported by the absence of statistically significant differences in the concentration of $\mathrm{LH}$ in the plasma of sheep of the 3 breeds at any of the 4 sampling times after the injection of LH-RH. There was, however, the indication that the pattern of decline in the concentration of LH differed among the breeds, for the quadratic (but not the linear) components to the curves differed $(P<0.05)$.

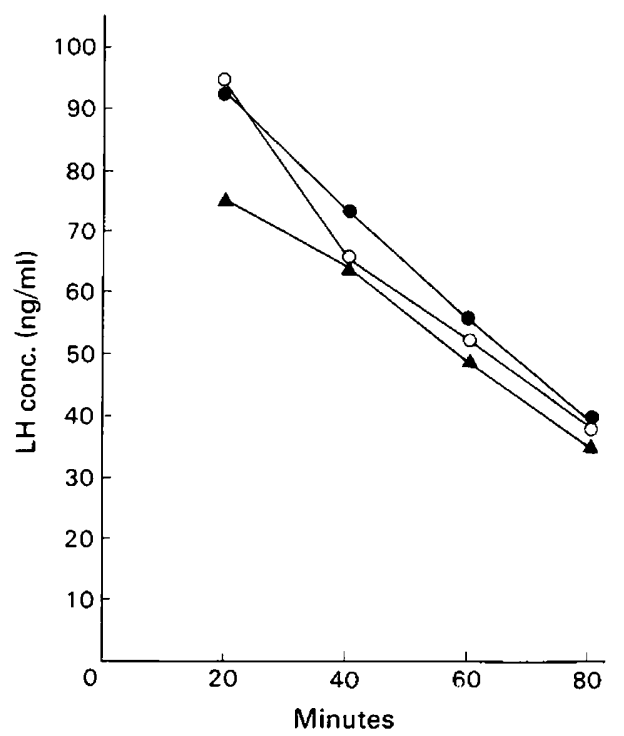

Text-fig. 2. The effect of breed (, Blackface; O, Finn; $\mathbf{A}$, Merino) on the average LH response of sheep to the injection of LH-RH (at $0 \mathrm{~min}$ ).

Time of year. The effect of the time of year of treatment on the 'summed concentration' after injection bordered statistical significance when assessed over the 3 breeds $(0.05<P<0.1)$ (Table 1); it appeared to increase from June to August to November ('summed concentrations' $230.6,249.4$ and $260.3 \mathrm{ng} / \mathrm{ml}$ respectively). As with the effects of breed the effects of time of year were also examined in terms of the concentration at each of the 4 sampling times after the injection of LH-RH, the variation among the 3 breeds being removed. The mean concentration at each sampling time over breeds is illustrated in Text-fig. 3 for each time of year. Although the initial response to treatment (the concentration at 20 and 40 min after injection) was similar at all 3 times of year $(P>0.05)$, it was more prolonged as the year advanced, so that at $80 \mathrm{~min}$ after injection, the concentration in November was $50 \%$ higher than in June (45 versus 30 $\mathrm{ng} / \mathrm{ml} ; P<0.01)$. This analysis of the effects of season on the concentration of $\mathrm{LH}$ at the different times after stimulation with LH-RH shows that the indication of a progressive increase in the 'summed concentration' is probably real, and that this arose principally from more prolonged secretion rather than a higher initial response. 


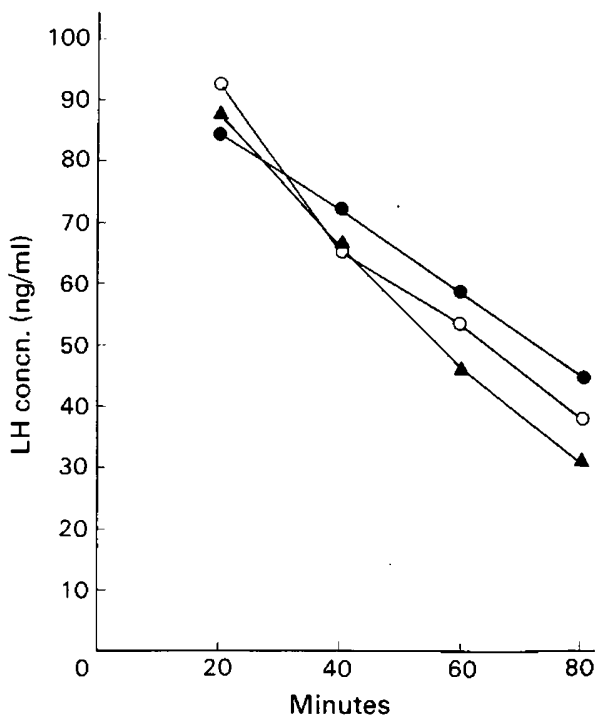

Text-fig. 3. The effect of 'season' ( $\boldsymbol{\Theta}$, November; $O$, August; $\Delta$, June) on the average LH response of Finn, Blackface and Merino ewes to the injection of LH-RH (at $0 \mathrm{~min}$ ).

Interactions. The possible presence of interactions between the 3 main factors was examined, and the only one to reach statistical significance was that between dose and time of year on the concentration at $20 \mathrm{~min}$ after injection, an interaction which has no obvious interpretation. There were no statistically significant interactions between the main effects on the 'summed concentration' (Table 1).

Scale. The analysis of some earlier studies has been based on transformed data. Analysis of the present results following log transformation of the data did not alter their interpretation.

\section{Discussion}

The response to LH-RH was, as might have been expected, markedly affected by the dose; a 16fold increase in dose approximately doubled the response. In addition to changing the magnitude of the response, the characteristics of the response also changed. The first 4-fold increase in the dose from 1.56 to $6.25 \mu \mathrm{g} \mathrm{LH}-\mathrm{RH}$ appeared to increase the amount of LH initially released, the decay curves being parallel. The second 4-fold increase in the dose from 6.25 to $25 \mu \mathrm{g} \mathrm{LH}-\mathrm{RH}$ had little further effect on the amount of LH initially released, but the high concentration of LH in peripheral plasma was maintained for a longer period of time, indicating that this highest dose prolonged the period of release (assuming that clearance rates were not affected).

The breed of the sheep had little effect on the response, despite the 3-fold difference in the ovulation rates of the 3 breeds studied, suggesting that the basic response of the pituitary gland to LH-RH does not contribute to the difference in fecundity. The higher response to LH-RH of Finn-cross ram lambs relative to Merino-cross ram lambs (Carr, Land \& Sales, 1975) may therefore arise from differential changes in the sensitivity of the pituitary gland during prepubertal development, possibly associated with a difference in either peripheral steroid levels or in the effect of these steroids on the gland.

The effect of time of year on the duration of secretion of $\mathrm{LH}$ contrasts with the earlier conclusion that there were no effects of the stage of anoestrus on the response to LH-RH (Reeves, Tarnavsky \& Chakraborty, 1974). However, the two experiments differed in four major 
respects: Reeves et al. (1974) gave their LH-RH by a different route (i.m. injection), used a higher dose $(50 \mu \mathrm{g})$, and studied intact ewes over a narrower range of conditions, all of which are likely to influence the response. The present data do, however, agree with the report of Lincoln (1977) that the duration of the response of intact rams to LH-RH is greater in rams kept under stimulatory short-day lighting relative to those kept on long days. In addition, they indicate that the more prolonged secretion of LH may arise from a primary change in the activity of the hypothalamus or the pituitary gland rather than simply as a secondary response to gonadal steroids.

The presence of seasonal variation in the response to LH-RH contrasts with the absence of marked genetic variation in the present study, indicating a difference in the physiological mediation of the two sources of variation in reproductive activity. Variation in the unmodulated sensitivity of the pituitary gland to $\mathrm{LH}-\mathrm{RH}$ did not apparently contribute to genetic variation in sensitivity of the oestrogen-induced positive discharge of LH reported earlier (Land et al., 1975), but may have contributed to the seasonal variation.

Not only was the response of the 3 breeds similar over all seasons, but there was no indication of a breed by season interaction in the response to LH-RH, even though the natural breeding seasons of sheep of these 3 breeds differ markedly (Wheeler \& Land, 1977). The present experiment did not therefore detect a contribution of variation in releasable LH stored in the pituitary gland to the genetic differences in the breeding seasons of the 3 breeds.

Finally, the greater duration of the response with higher dose and high proximity to the breeding season indicates that both sources may have contributed to the change in the response of ram lambs to LH-RH with age observed by Galloway \& Pelletier (1974), when age, season and dose were all confounded.

We thank Marjorie Fordyce, Mairwen Swaney, G. Baxter and R. D. Preece for technical help, D. Ramshaw for statistical assistance, $\mathrm{Mr}$ J. Best, Hoechst, for supplies of LH-RH, Dr M. Jutisz for purified ovine LH (M3), and the Pituitary Hormone Distribution Program (NIH) for hormone preparations.

\section{References}

Carr, W.R. \& Land, R.B. (1975) Plasma luteinizing hormone levels and testis diameters of ram lambs of different breeds. J. Reprod. Fert. 42, 325-333.

Carr, W.R., Land, R.B. \& Sales, D.I. (1975) The effect of gonadotrophin releasing hormone $(\mathrm{GnRH})$ on plasma levels of luteinizing hormone $(\mathrm{LH})$ in lambs of breeds with high and low ovulation rates. Annls Biol. anim. Biochim. Biophys. 16, 167, Abstr.

Finney, D.J. (1960) An Introduction to the Theory of Experimental Design, p. 179. University of Chicago Press, Chicago.

Galloway, D.B. \& Pelletier, J. (1974) Influence of age on the pituitary response of male lambs to synthetic $\mathrm{LH}$ RH injection. Horm. Metab. Res. 6, 240-241.

Jutisz, M. \& Courte, C. (1968) Hormone lutéinisante (LH) du mouton. 1. Obtention a l'état apparament homogène. Etude physio-chemique et biologique. Gen. comp. Endocr. 11, 562-574.

Land, R.B., Pelletier, J., Thimonier, J. \& Mauléon, P. (1973) A quantitative study of genetic differences in the incidence of oestrus, ovulation and plasma luteinizing hormone concentration in the sheep. $J$. Endocr. 58, 305-317.

Land, R.B., Wheeler, A.G. \& Carr, W.R. (1976) Seasonal variation in the oestrogen induced $\mathbf{L H}$ discharge of ovariectomized Finnish Landrace and
Scottish Blackface ewes. Annls Biol. anim. Biochim. Biophys. 16, 521-528.

Lincoln, G.A. (1977) Changes in pituitary responses to luteinizing hormone releasing hormone in rams exposed to artificial photoperiods. J. Endocr. 73, 519-527.

Reeves, J.J., Tarnavsky, G.K. \& Chakraborty, P.K. (1974) Serum LH in ewes treated with synthetic luteinizing hormone-releasing hormone/follicle stimulating hormone-releasing hormone ( $\mathrm{LH}$ $\mathrm{RH} / \mathrm{FSH}-\mathrm{RH}$ ) at three periods of anoestrus. J. Anim. Sci. 38, 369-373.

Rodbard, D. (1971) Statistical aspects of radioimmunoassays. In Principles of Competitive ProteinBinding Assays, pp. 204-210. Eds W. D. Odell \& W. H. Doughaday. Lippincott, Philadelphia.

Snedecor, G.W. \& Cochran, W.G. (1967) Statistical Methods, 6th edn. Iowa State University Press, Ames, Iowa.

Wheeler, A.G. \& Land, R.B. (1977) Seasonal variance in oestrus and ovarian activity of Finnish Landrace, Tasmanian Merino and Scottish Blackface ewes. Anim. Prod. 24, 363-376.

Yuthasastrakosol, P., Palmer, W.M. \& Howland, B.E. (1977) Release of LH in anoestrous and cyclic ewes. J. Reprod. Fert. 50, 319-321. 